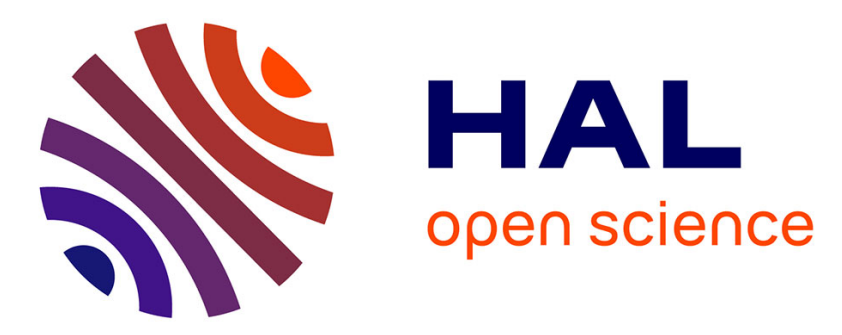

\title{
Dual mode, multiple electrodes Quartz Sensor.
}

Ioan Alexandru Ivan, Roger Bourquin, Bernard Dulmet

\section{To cite this version:}

Ioan Alexandru Ivan, Roger Bourquin, Bernard Dulmet. Dual mode, multiple electrodes Quartz Sensor.. IEEE Ultrasonics Symposium, 2005, 2, pp.1262-1265. 10.1109/ULTSYM.2005.1603081. hal-00797930

\section{HAL Id: hal-00797930 \\ https://hal.science/hal-00797930}

Submitted on 7 Mar 2013

HAL is a multi-disciplinary open access archive for the deposit and dissemination of scientific research documents, whether they are published or not. The documents may come from teaching and research institutions in France or abroad, or from public or private research centers.
L'archive ouverte pluridisciplinaire HAL, est destinée au dépôt et à la diffusion de documents scientifiques de niveau recherche, publiés ou non, émanant des établissements d'enseignement et de recherche français ou étrangers, des laboratoires publics ou privés. 


\title{
DuAl Mode, Multiple Electrodes QuARTZ Sensor
}

\author{
A. IVAN ${ }^{\circ}$ R. BOURQUIN*, B. DULMET* \\ - Electrical Engineering Faculty, UV T, \\ B-dul Unirii 18-20, 0200 Targoviste, Romania \\ * Department LCEP, FEMTO-ST / ENSMM, \\ 26 Chemin de l'Epitaphe, 25000 Besançon, France
}

e-mail: $\underline{\text { ivan@ valahia.ro }}$

\begin{abstract}
We present a method to design the electrodes shape of contoured BAW resonators intended to serve as temperature compensated force sensors. Those are based on simultaneous operation on two families of modes: fast shear B-mode and slow shear C-mode. Use of anharmonic modes instead of main overtone ones provides the possibility of spatial separation of vibrating areas, each mode being driven by separated pairs of electrodes. Electronic circuitry is greatly simplified and force deriving is straightforward.
\end{abstract}

\section{KEYWORDS: BAW resonator, anharmonic modes, force sensor.}

\section{INTRODUCTION}

High frequency bulk acoustic waves piezoelectric resonators are used as frequency-output sensors for direct measurement of force or related quantities such as acceleration or pressure. By applying a compressional diametrical force on a classical round resonator, a frequency shift is to be noticed depending on force orientation.

The performances of such sensors on wide temperature ranges are generally limited by their frequency-temperature sensitivity, even when the crystals are realized in (quasi) thermally-compensated cuts. A way to avoid this limitation is to use the quartz as its own temperature sensor to compensate the residual variation of frequency due to temperature change. This can be done by operating the resonator at two resonant modes of different families ( $B$ and $C$ ) and by extracting the useful information from the two frequencies of modes. The treatment is simplified if the corresponding transfer matrix is quasi-diagonal.

Then one mode must be essentially sensitive to the force, while the other must be essentially sensitive to the temperature. Electronic operation can be achieved by using a single pair of electrodes systems and appropriate filtering. In that case, main overtone modes, so-called $(n, 0,0)$ and belonging to different thickness-propagation families ( $B$ and $C$ ) are systematically used. The use of a pair of anharmonic modes offers a better way with superior optimization, since, in that case, one can efficiently connect the two oscillators to separate electrode systems on the sensing resonator, which greatly simplifies the design of the electronics. This can be achieved if the vibration amplitudes of the two modes are mainly located in separate regions in the plane of the resonator.
We present here a method for designing the shape of electrodes derived from the knowledge of modes patterns corresponding to given mode family, overtone number and rank of anharmonic. These ones are obtained experimentally by using X-ray. Then data is employed in association with the analytical model of Stevens and Tiersten [10] to get the precise amplitude distribution of mechanical displacement for the design of electrodes and to compute the force sensitivity of the sensor [3], [8].

Practical application was made for a plano-convex SC-cut where the $\mathrm{C}$-mode is thermally quasi-compensated and $\mathrm{B}$ mode has a fairly linear frequency-temperature slope. If the applied force has a certain azimuth angle then the force sensitivity of the $B$ mode will be insignificant compared to that of the $\mathrm{C}$ mode.

Taking advantage of spatial symmetry properties of wellchosen pair of modes (for instance using C-mode $(3,0,1)$ and B-mode $(3,1,0))$ leads to a dual-mode design which virtually eliminates the intermodulation between the two oscillator signals, while keeping the transfer matrix as nearly diagonal as possible.

\section{VIBRATION AMPLITUDE MODELLING}

In figure $1,\left(x_{1}^{\prime}, x_{3}^{\prime}\right)$ represent the local coordinates of the modes rotated by the angle $\psi_{n}^{(i)}$ with respect to the resonator system of axis $\left(X_{1}, X_{3}\right)$.

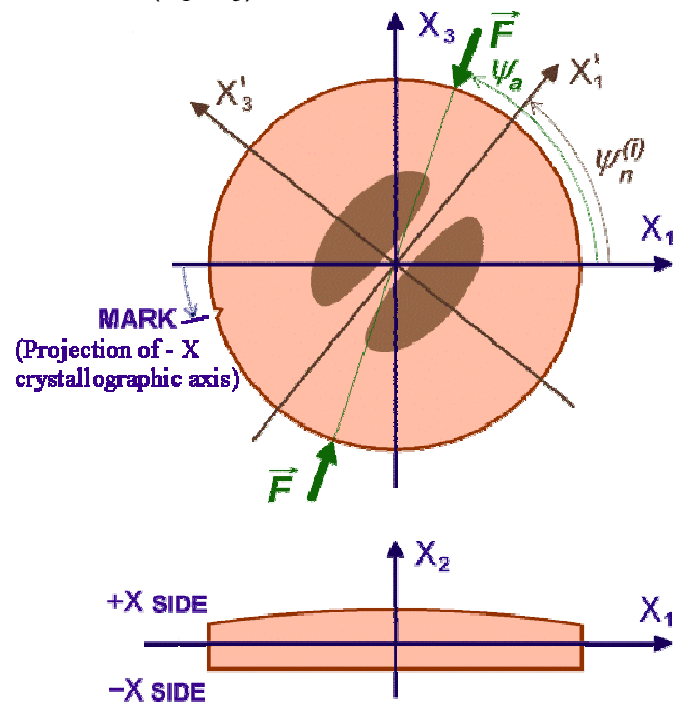

Figure 1. Contoured resonator geometry. 
According to Stevens and Tiersten theory [10], [2] the normalized distribution of vibration amplitude is given by:

$u_{n m p}^{(i)}\left(x_{1}^{\prime}, x_{3}^{\prime}, x_{2}\right)=H_{m}\left(\sqrt{\alpha_{n}^{(i)}} x_{1}^{\prime}\right) \cdot H_{p}\left(\sqrt{\beta_{n}^{(i)}} x_{3}^{\prime}\right) \cdot \sin \frac{n \pi x_{2}}{2 h} \cdot e^{-\frac{\alpha_{n}^{(i)} x_{1}^{\prime 2}+\beta_{n}^{(i)} x_{3}^{\prime}{ }^{2}}{2}}$ where:

- $i=B$ or $C$ is the type of shear (fast or slow);

- $n=1,3,5, \ldots$ is the overtone number while $m$ and $p$ describe the vibration rank along $X^{\prime}{ }_{1}$ and $X_{3}{ }_{3}$ axis;

- $H_{m}, H_{p}$ are Hermite polynomials $\left(H_{0}(x)=1, H_{l}(x)=2 x\right.$, $H_{2}(x)=4 x^{2}-2$ etc.);

- $2 h$ is the thickness of the resonator;

- $\alpha_{n}^{(i)}$ and $\beta_{n}^{(i)}$ are constants that depend on the material, on the cut, on the type of shear, on the overtone $n$ and on the curvature radius $R$, which govern the shape of the mode [2]. Values $\alpha_{n}^{(i)}, \beta_{n}^{(i)}$ and $\psi_{n}^{(i)}$ of are derived from experimental data (topographies and resonant frequencies).

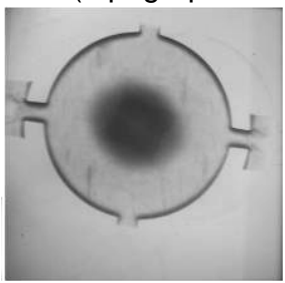

$5.4875 \mathrm{MHz}$

$(\mathrm{B}, 3,0,0)$

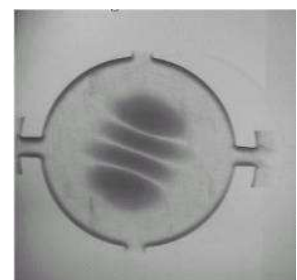

$5.6012 \mathrm{MHz}$

$(\mathrm{B}, 3,0,3)$

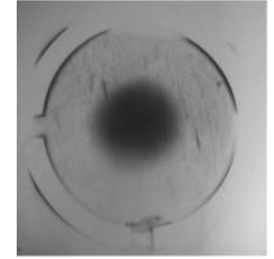

$5.0068 \mathrm{MHz}$

$(\mathrm{C}, 3,0,0)$

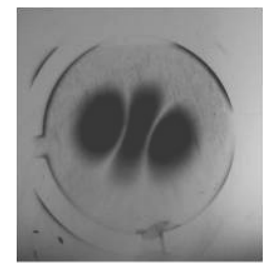

$5.0940 \mathrm{MHz}$

$(\mathrm{C}, 3,2,0)$

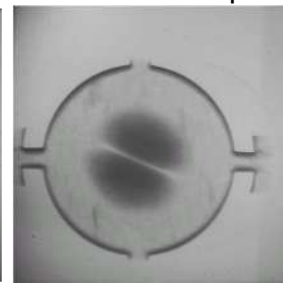

$5.5241 \mathrm{MHz}$ $(B, 3,0,1)$

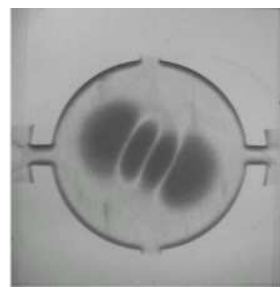

$5.6462 \mathrm{MHz}$ $(\mathrm{B}, 3,3,0)$

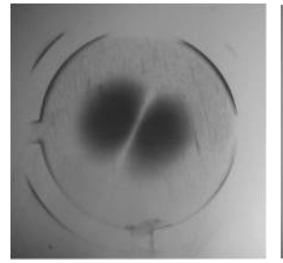

$5.0503 \mathrm{MHz}$ $(\mathrm{C}, 3,1,0)$

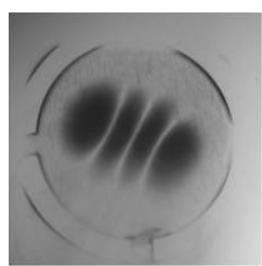

$5.1409 \mathrm{MHz}$

$(\mathrm{C}, 3,3,0)$

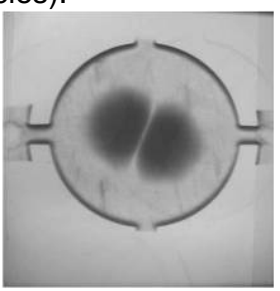

$5.54046 \mathrm{MHz}$ $(B, 3,1,0)$

Resonator Axis

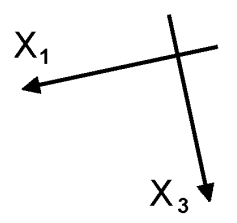

Figures 2. X-rays topographies on a $5 \mathrm{MHz}$ resonator.

An extensive series of $\mathrm{X}$-ray topographies (XRT) were first performed on a $5 \mathrm{MHz}$ multielectrode resonator to investigate experimentally the modes shapes and orientation angles.
Most representative mode patterns are shown in figures 2.

According to Lewis [7], the motional resistance $R_{l}$ is computed from integrals over the resonator volume:

$$
R_{1}=\frac{1}{Q \omega_{n m p}} \cdot \frac{\int_{V} c_{i j k l} S_{i j}^{n m p} S_{k l}^{n m p} \mathrm{~d} V}{\left(\int_{V} e_{k i j} E_{k}^{S} S_{i j}^{n m p} \mathrm{~d} V\right)^{2}}
$$

Where $S_{i j}{ }^{n m p}$ is the dynamic deformation depending on $u_{n m p}$ of the mode and $E_{k}{ }^{S}$ is the static electric field in the resonator when a unity voltage is applied between the electrodes. $Q$ is the quality factor of the resonator.

\section{MULTIELECTRODE DESIGN}

The criteria for a proper anharmonic modes multielectrode structure design are diverse and subject to tradeoff between them:

- nodal lines of thickness shear modes of different families must be as much orthogonal as possible;

- selected modes have to have low anharmonic ranks, provided that higher ranks give too complex distribution shapes;

- electrode shape must electrically excite as much as possible the selected anharmonic mode according with Lewis formula[7] but also to suppress unwanted others;

- electrode area must be taken into account, knowing that increasing the surface will increase the static capacitance Co while lowering the surface will diminue the mode amplitude;

- electrodes must be sufficiently spatially separated to avoid coupling capacitance between them.

First, we need to compute analitically the distribution of vibration amplitude of selected anharmonic modes pair. Several choices are possible; in our case selected pair was $(C, 3,0,1)$ and $(B, 3,1,0)$ - figures $3 . a$ and $3 . b$ respectively. The design steps included an algorithm to calculate the difference of modulus amplitudes $\left|u_{301}^{C}\right|-\left|u_{310}^{B}\right|$, which is represented on figure 3.c. The area covered by electrodes must satisfy the following conditions imposed to vibration amplitude:

1) $\left|u_{310}^{B}\right|>k \cdot\left|u_{301}^{C}\right|$ and $\left|u_{310}^{B}\right| \geq l e v$ for B-mode electrode pairs,

2) $\left|u_{301}^{C}\right|>k \cdot\left|u_{310}^{B}\right|$ and $\left|u_{301}^{C}\right| \geq l e v$ for C-mode electrode pairs,

where $k$ is a called a separation factor and lev is the minimum level factor. Using Lewis formula, the motional resistance of mode is calculated. Proper values are: $k=1.5$ and lev $=10 \%$ of peak amplitude. The resulted electrode shape is represented in figure 3.d. Electrode pairs P1 and P3 connected in antiparallel will drive the $(B, 3,1,0)$ mode while $(C, 3,0,1)$ mode will be excited by the electrodes P2 and P4. Final picture of electrodes plus associated connection pads is shown in figure 3.e.

Several multielectrode samples were constructed from quartz SC-cut blanks of $13.2 \mathrm{~mm}$ diameter, $0.7 \mathrm{~mm}$ thickness and $300 \mathrm{~mm}$ curvature radius. Electrodes were made of gold on a chrome buffer by using photolithography technique. Selected $(C, 3,0,1)$ and $(B, 3,1,0)$ modes frequencies are located at 7.2947 $\mathrm{MHz}$ and 7.975 MHz respectively, as can be seen from the spectrums (figures 4-5, frequencies marked by circle). Quality factors in air range around 200,000. 

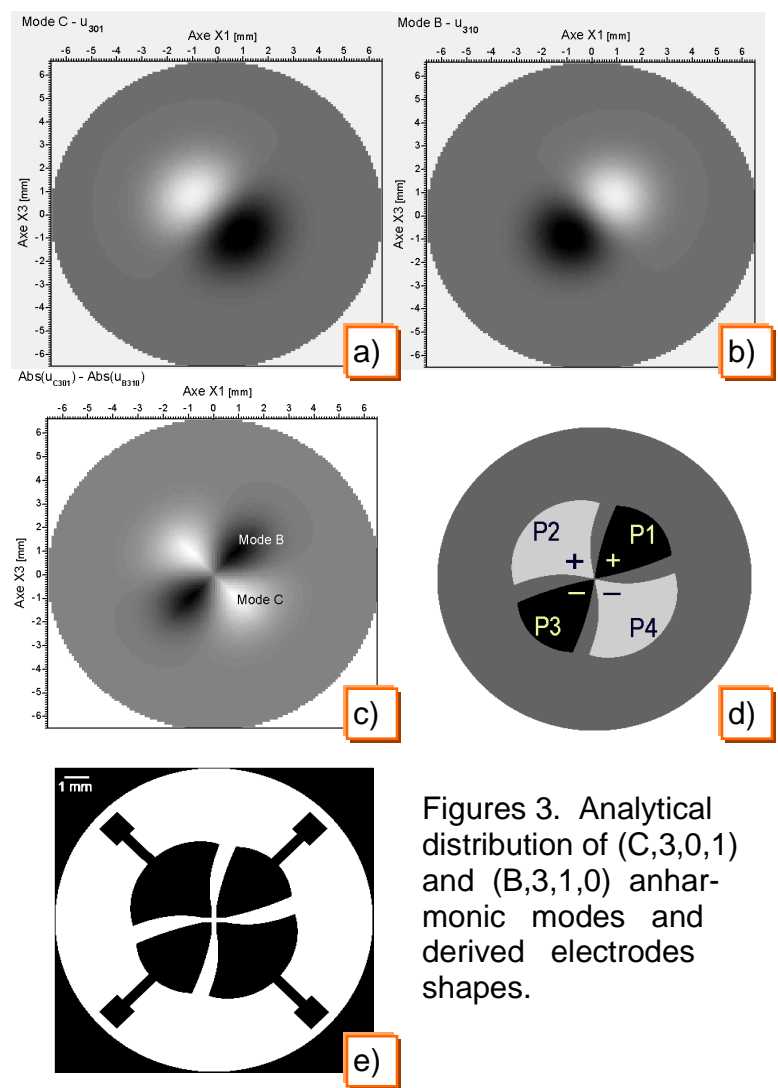

Figures 3. Analytical distribution of $(\mathrm{C}, 3,0,1)$ and $(B, 3,1,0)$ anharmonic modes and derived electrodes shapes.

All other modes present lower or equal admittances than selected ones. Unwanted modes of the highest amplitude are $(B, 3,0,1)$ and $(C, 3,1,0)$, which are separated by $\sim 700 \mathrm{kHz}$ from the selected modes and may be further filtered with passive components. Much lower amplitudes present the modes $(B, 3,0,3),(B, 3,3,0),(C, 3,0,3)$ and $(C, 3,3,0)$. Due to the fact that opposite pairs of electrodes are driven in antiparallel, ranks of anharmonic of even numbers such as $(C, 3,2,0)$ or $(B, 3,2,0)$ are completely suppressed. X-ray topographies of selected modes were performed and are shown on figure 6 .

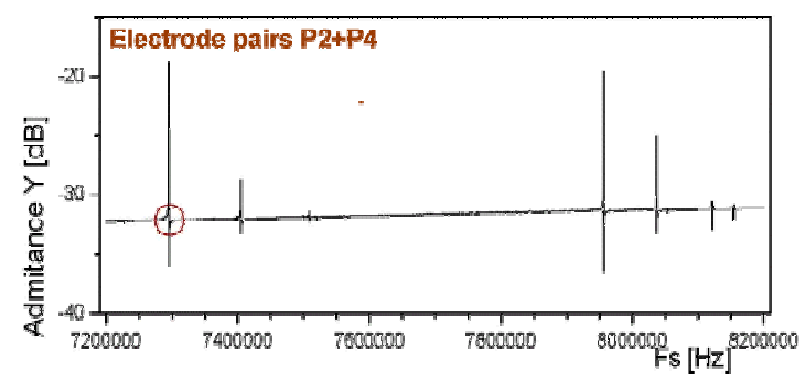

Figure 4. Admittance spectrum. Electrode pair for $(C, 3,0,1)$.

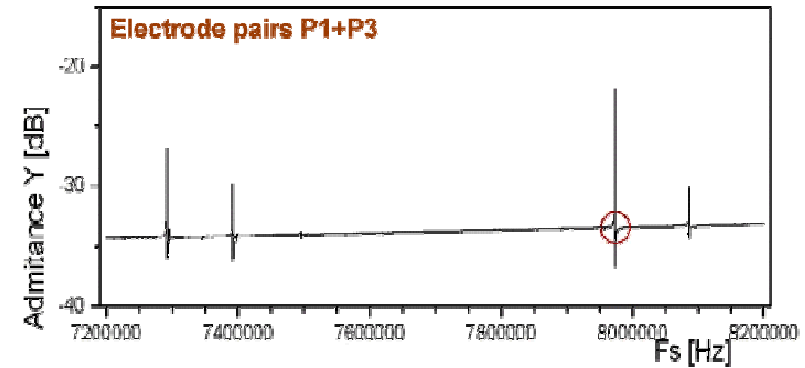

Figure 5. Admittance spectrum. Electrode pair for $(B, 3,1,0)$.

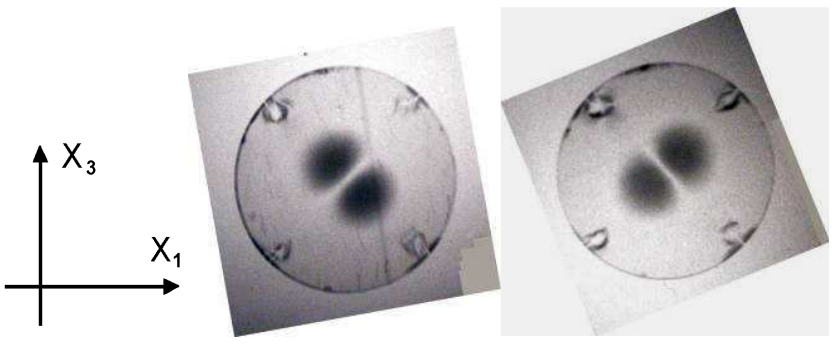

Figures 6. XRT on $(C, 3,0,1)$ and $(B, 3,1,0)$.

\section{SENSOR TRANSFER FUNCTION}

For SC-cut, B-mode is a thermometric one and was fitted under a $2^{\text {nd }}$ order polynomial (figure 7 ) while the $C$ mode is quasi-compensated, being described by cubic parabola (figure 8). Force sensitivity is linear up to $95 \%$ of its crushing load [8].

$$
\Delta f_{B}=f_{B}-f_{B 0}=b_{1} t+b_{2} t^{2}+S_{F B} F
$$

$$
\Delta f_{C}=f_{C}-f_{C 0}=c_{1} t+c_{2} t^{2}+c_{3} t^{3}+S_{F C} F
$$

\begin{tabular}{|c|c|c|c|}
\hline$f_{\mathrm{B} 0}=7977560$ & $b_{1}=-203.126$ & $b_{2}=-0.22721$ & --- \\
\hline$f_{\mathrm{C} 0}=7294625$ & $c_{1}=10.0365$ & $c_{2}=-0.11365$ & $c_{2}=3.541 \mathrm{E}-4$ \\
\hline$[\mathrm{Hz}]$ at $273.15 \mathrm{~K}$ & {$[\mathrm{~Hz} / \mathrm{K}]$} & {$\left[\mathrm{Hz} / \mathrm{K}^{2}\right]$} & {$\left[\mathrm{Hz} / \mathrm{K}^{3}\right]$} \\
\hline
\end{tabular}

As seen from figure 9 where the Ratajski force sensitivity coefficients $K f$ [8], [3] are represented vs. $\psi_{a}$ (angle of applied force). For a azimuth angle of $\psi_{a}=75^{\circ}$ the force sensitivity $S_{F B}$ of $(B, 3,1,0)$ mode is negligible while the force sensitivity $S_{F C}$ of $(\mathrm{C}, 3,0,1)$ mode is close to maximum.

$$
S_{F B}=\frac{\Delta f_{B}}{\Delta F} \cong 0 \quad<\quad S_{F C}=\frac{\Delta f_{C}}{\Delta F} \cong-14.95 \mathrm{~Hz} / \mathrm{N}
$$

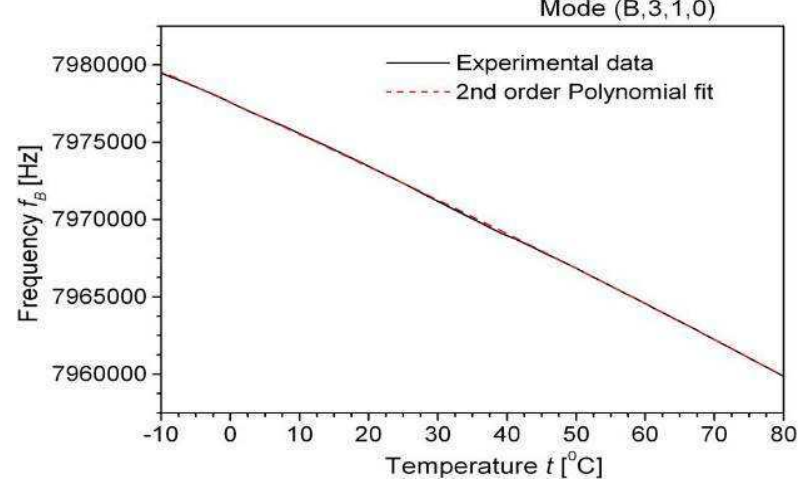

Figure 7. Frequency-Temperature Characteristic of $(B, 3,1,0)$.

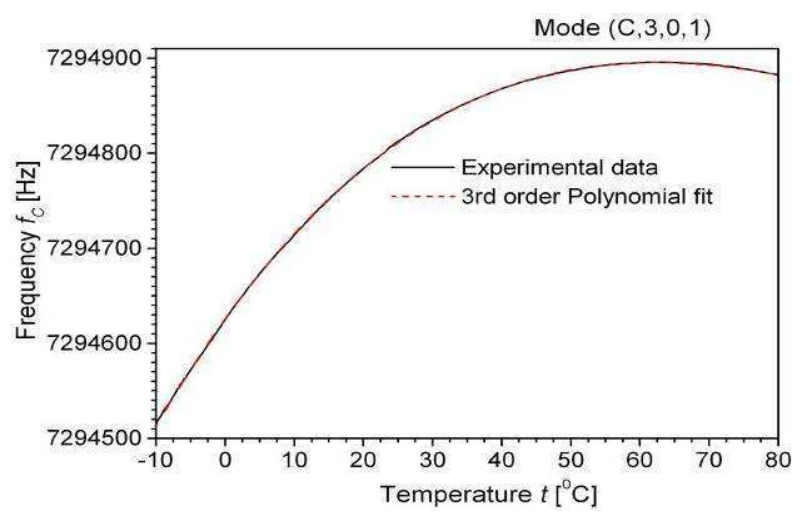

Figure 8. Frequency-Temperature Characteristic of $(C, 3,0,1)$. 


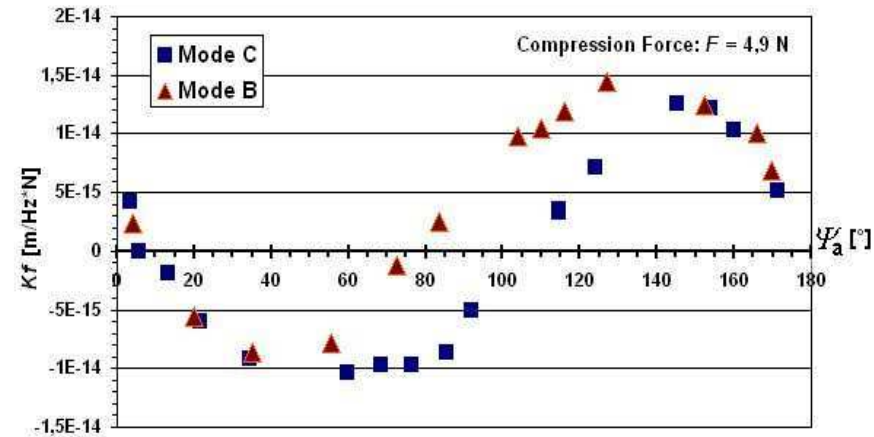

Figure 9. Force sensitivity coefficients $K f$ of

$(\mathrm{C}, 3,0,1)$ and $(\mathrm{B}, 3,1,0)$ modes w.r.t. azimuth angle $\psi_{a}$.

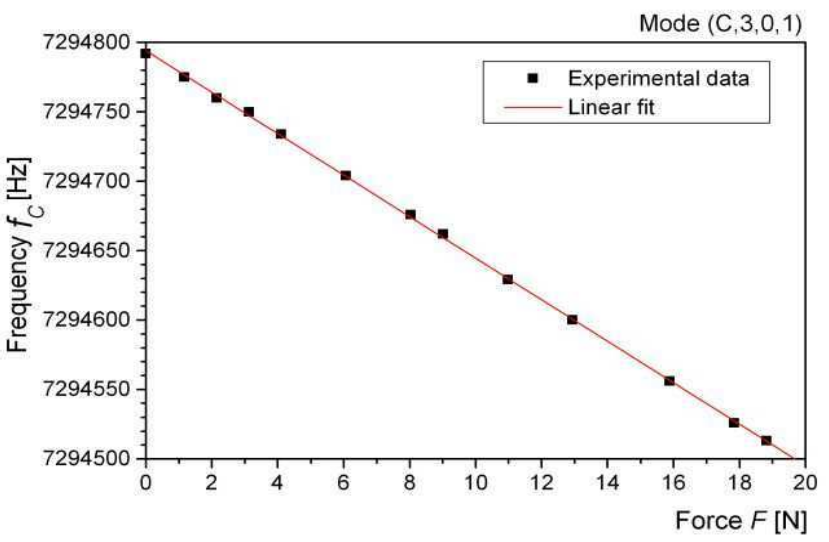

Figure 10. Frequency-Force Characteristic at $\psi_{a}=75^{\circ}$.

For example, an azimuth error of $\pm 2^{0}$ leads to a non-zero $S_{F B}$, that finally causes the errors: $\delta_{t}=-0,004{ }^{\circ} \mathrm{C}$ on temperature measurement and $\varepsilon_{F}=0.33 \%$ force relative error.

Temperature $t$ value is obtained from the B-mode frequency:

$$
t=\frac{-b_{1}-\sqrt{b_{1}^{2}+4 b_{2} \cdot \Delta f_{B}}}{2 b_{2}}
$$

Then, the force transfer function results from the above temperature formula and the $\mathrm{C}$-mode frequency. A plot of the function depending on frequency variations is shown in figure 11.

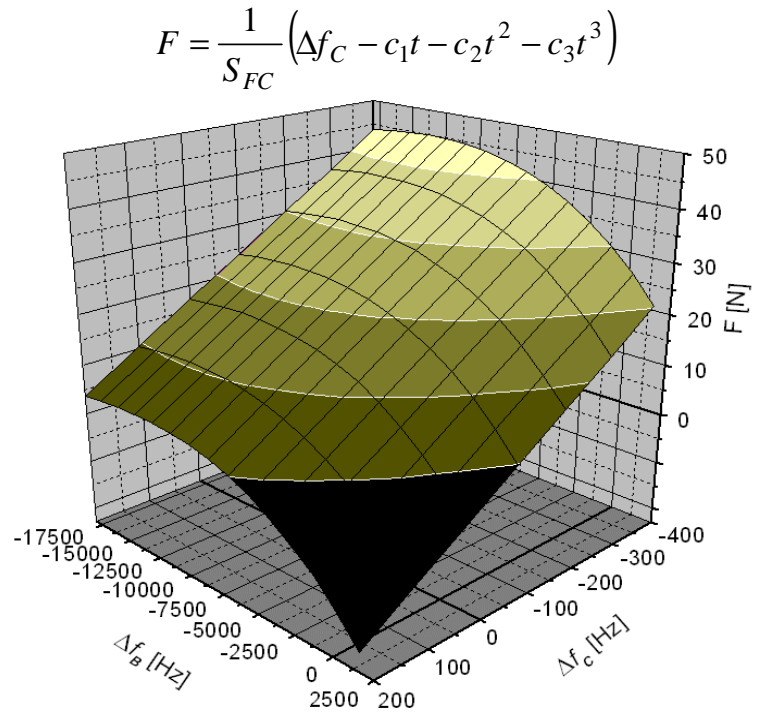

Figure 11. Force-frequencies transfer funct. $F=\left(\Delta f_{B}, \Delta f_{C}\right)$

\section{CONCLUSIONS}

This approach efficiently combines the designing effort on the crystal resonator and driving electronics in order to make dualmode multiple electrodes sensors competitive in comparison with the more complicated electronically discriminated dualmode sensors relying on a single pair of wires. Using two independent low-cost oscillators connected to a microcontroller, a precise measurement system of force is implemented.

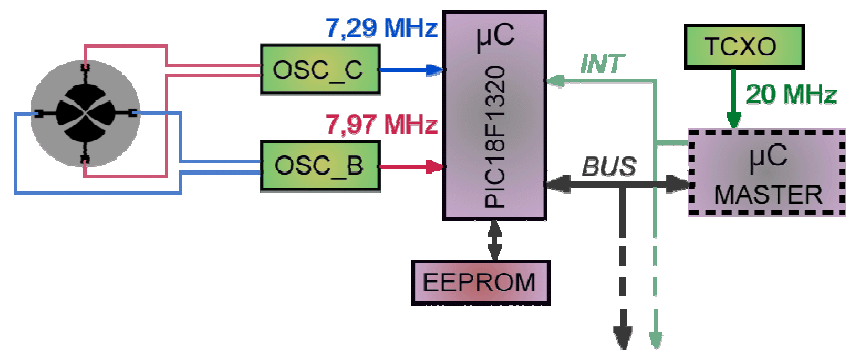

Figure 12. Digital processing circuit block diagram.

\section{ACKNOWLEDGEMENTS}

This work received support from E.U. GROWTH Program QxSens - Multi-channel measurement and control system based on resonant piezoelectric crystal sensors (G6RD-CT2002-00648).

\section{REFERENCES}

[1] R. J. Besson, J. J. Boy, B. Glotin, Y. Jinzaki, B. K. Sinha and M. Valdois, A dual-mode thickness-shear quartz pressure sensor, IEEE Trans. on U.F.F.C. Vol.40, №5, p.548-591, (1993)

[2] R. Bourquin, J.J. Boy, B. Dulmet, SC-cut resonator with reduction of B-mode electrical response, Proc. IEEE Int. Freq. Control Symp., p. 704-709, (1997)

[3] R. Bourquin, B.Dulmet, Force Sensitivity of trapped energy vibrations in a contoured resonator, Proc. $41^{\text {st }}$ Ann. Freq.Cont.Symp. p. 289-294, (1987)

[4] B.Dulmet, R.Bourquin, N.Shibanova, Frequency-output force sensor using a multimode doubly rotated quartz sensor,Sensors and Actuators, A 48, p.109-116,(1995)

[5] E. P. EerNisse, Analysis of Thickness Modes of Contoured, DoublyRotated, Quartz resonators, IEEE Trans. on U.F.F.C. Vol. 48, $N^{\circ} 5$, p.1351-1361, (2001)

[6] G. Genestier, Application de la topographie par rayons $X$ a l'etude des modes de vibration dans un resonateur a onde de volume, These de doctorat, University of Franche-Comté, Besançon - France, (1982)

[7] J. A. Lewis, The effect of driving electrode shape on the electrical properties of piezoelectric crystals, B.S.T.S. p.1259-1280, (1961)

[8] J. M. Ratajski, The force sensitivity of AT-cut crystals, Proc. 20th Ann.Freq. Symp NJ USA, p. 33-49, (1966)

[9] B. K. Sinha, Doubly Rotated Contoured Quartz Resonators, IEEE Trans. on U.F.F.C. Vol. 48, N5, p.1162-1180, (200 1)

[10] D. S. Stevens, H. F. Tiersten, An analysis of doubly rotated quartz resonators utilizing essentially thickness modes with transverse variation, J.Acous. Soc. Am., 79, p. 1811-1826, (1986)

[11] J. Zelenka, Piezoelectric Resonators and their Applications, Czechoslovak Academy of Sciences, Prague (1986) 